million pounds would be held in trust for the establishment of a medical research school. A little later, having been informed that even this princely sum would not be sufficient, he increased it to two millions, remarking that he would hate to leave the scheme incomplete. This new school was the largest gift ever made by an individual in this country. Aware that large benefactions always carry with them the danger of impoverishment in other directions, he guarded against this at Oxford by an additional offer of $£ 100,000$ to meet the demands which his scheme might make on other departments of the University.

In 1930 he had purchased the Radcliffe Observatory and surrounding land and had made a wise and prophetic move by handing it over partly to the University and partly to the Radcliffe Infirmary. This enabled the latter to extend on its existing site without undue crowding and with provision of open spaces. $\mathrm{He}$ had also given to the Radcliffe one of the best maternity homes in the country. This was in memory of his mother, Emily Ann Morris. At the former observatory the Nuffield Institute of Medical Research was established in 1935, its purpose being the promotion of clinical research, especially in the domain of therapeutics. The extraordinary variety and magnitude of his benefactions for medical purposes alone may be seen from the list at page 553, which omits many for non-medical purposes.

It is difficult to keep pace with such munificence. By 1938 it was estimated that his gifts to the University alone amounted to three and a half millions. In the following year he placed in the hands of trustees shares in Morris Motors Limited to the value of about one and a quarter million pounds as the nucleus of the Nuffield Provincial Hospitals' Trust, whose purposes were somewhat analogous to those of the King's Fund for the metropolitan area. In the middle of the war he handed over to trustees shareholdings in the Nuffield organization to the value of ten million pounds as a capital fund for the Nuffield Foundation to promote medical research and teaching, the organization and development of medical and health services, scientific research and teaching in the interests of trade and industry, social studies, and the care and comfort of aged persons. The awakened interest in geriatrics owes its stimulus not a little to Lord Nuffield.

He was made a baronet in 1929, a baron in 1934, and a viscount in 1938. In 1941 he was appointed G.B.E., and in 1958 was admitted a Companion of Honour. Many associations delighted to honour him. He was an honorary member of the British Orthopaedic Association and of the Association of Anaesthetists, an honorary fellow of the Royal Scottish Society of Arts, and an honorary freeman of the Society of Apothecaries of London. He was made vice-president of the Papworth Village Settlement, to which he had given $£ 25,000$. In 1942 he was the nineteenth recipient, in 140 years, of the honorary medal of the Royal College of Surgeons, and seven years later, with the opening of the hostel in Lincoln's Inn Fields, made possible by his generosity, he became honorary fellow of the College. On that occasion he disclosed what had been the ambition of the young man who founded the Morris Garages under the walls of Magdalen in 1898-it was to be a surgeon.

\section{GENETICS AND MEDICINE}

We are extraordinarily ignorant of the causes of common disorders even though, paradoxically, we may be able to treat them satisfactorily. Every day we are conscious of the problem of why some of our patients have started to develop a particular illness and we ought to make more effort to discover those who are " at risk" for constitutional disorders-in the same way as we do for infectious fevers. If only we could succeed in this way we should have gone a long way in preventive medicine. A great task of clinical genetics is to tackle this problem, and some knowledge of modern techniques is essential if we are to set about discovering, say, a proportion of potential cancer sufferers. The new Journal of Medical Genetics ${ }^{1}$ to be started next year should help to advance these aims. Furthermore, genetics makes medicine more interesting-it is intellectually stimulating in itself and it also enables us to see disease against a broader biological background.

There have been many recent genetical books of interest to the clinician, and C. D. Darlington ${ }^{2}$ in a - review of ten of them comments, "For the first time we can say that in one species, which happens to be our own, genetics has established connexions with the whole biology and with the whole history of the species. The possibilities of this momentous situation are thus opened for discussion and exploitation."

Taking Darlington's point the May issue of the American Journal of Medicine ${ }^{3}$ offers a symposium on genetics comprising a series of articles written by those actively engaged in research. It is interesting to see what experts on both sides of the Atlantic think that clinicians ought to know. First, the D.N.A. code. This explains at a molecular level the basic reason for variability, but there are sometimes difficulties in deciding whether an alteration in the sequence of the pairs of chemical bases is "abnormal" or not. The answer may

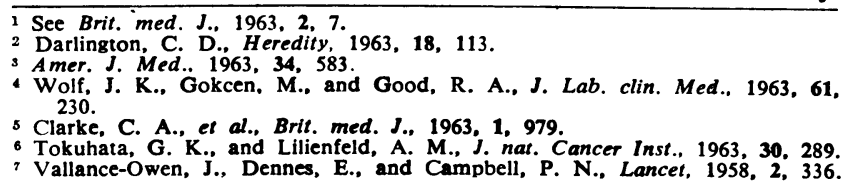


be that the product of a new gene is detrimental in certain circumstances but favourable in others, and if both the old and new genes persist we have a polymorphic system of the kind which is being detected in man with ever-increasing frequency. A knowledge of polymorphism is a "must" therefore for would-be geneticists. Next, the chromosomes. Mongolism, intersexuality, and other disorders resulting from nondisjunction occasionally come our way, and there is more than a suggestion that chromosomal abnormalities predispose to leukaemia. In this disease we ought also to know that there are other aetiological clues which are at least para-genetic. Close relatives of patients with leukaemia suffer more often than would be expected from immunological disorders, particularly hypogammaglobulinaemia, ${ }^{4}$ and there may be associations, too, with thymic disorders. The intelligent analysis of pedigrees may therefore provide real advances in understanding the problem of cancer in man, and in the symposium there is a special chapter on taking a genetic history.

It is important also to know something about the genetics of different races, because the patterns of constitutional disease may vary in different groups. Chorioncarcinoma, so rare in Great Britain, is relatively common in Hong Kong. What is its frequency in the Chinese living in Britain and, more interesting still, in the offspring of British-Chinese marriages? The varying geographical frequency of certain genes with important medical effects is also remarkable- $\mathrm{Rh}$ haemolytic disease is rare in Japan because so few people are Rh-negative. Natural protection against erythroblastosis is also afforded by $\mathrm{ABO}$ incompatibility between mother and foetus, and an attempt to mimic this by the giving of anti-D to women at risk seems rational and is the outcome of applying simple genetic principles to a clinical problem. ${ }^{5}$

Biochemical genetics has recently taken an interesting turn in emphasizing inherited variability in response to drugs (pharmacogenetics). Sometimes a polymorphic system is uncovered by clear-cut differences in the rate of metabolism-for example, fast or slow acetylation of isoniazid and sulphadimidine. With some other drugs the two types of individual are recognized because of toxic reactions in a minority of people-for example, to primaquine and suxamethonium. Why genes with a harmful effect are not gradually removed from the population when they are associated with reduced fertility is a matter of great interest. Usually the reason is unknown, but individuals sensitive to primaquine are probably protected from malaria because their red cells are deficient in glucose 6-phosphate dehydrogenase.

Next, a variety of statistical associations have been discovered in recent years. Sometimes a character of genetic origin such as a blood group occurs more com- monly than would be expected in a particular disease. Sometimes, as with the cigarette, the association is environmental. In either case it is important to understand the difficulties inherent in the problem, particularly as the distinction between nature and nurture may be difficult to clarify in practice. In a recent paper ${ }^{6}$ on smoking and lung cancer the genes are regarded as co-carcinogens, non-smokers with a family history of bronchial carcinoma being nearly as liable to the disease as heavy smokers with no affected relatives. The ionizing radiations of medical radiology and fallout also have mutagenic hazards about which the physician should know something.

The symposium in the American Journal of Medicine gives a useful account of many of these matters and also emphasizes some of the recent advances. For example, we are introduced to the idea of regulator and operator genes. These combine to switch on or off the old-fashioned structural genes according to whether the substrate on which the products of the gene would work is present or absent. New in the pharmacogenetics section is the abnormal haemoglobin Zurich which would have remained entirely unknown had not a certain Swiss family developed haemolytic anaemia in response to sulphonamides. In the same chapter there is more information on the inheritance of diabetes mellitus. We get away from the arguments about single gene versus multifactorial control and are introduced to the idea that there may be a simple method of inheritance (of a dominant type) not of diabetes itself but of the insulin antagonists - an idea originally introduced by J. Vallance-Owen. ${ }^{7}$. Finally, against an imposing background of research, McKusick's clinical chapter on genetic counselling more than holds its own, and it is refreshing to hear from him that the gain to medicine from genetics is only one part of the story; genetics, too, has gained much from medicine.

\section{STEROID TREATMENT IN DISSEMINATED SCLEROSIS}

Since 1951 there have been a number of reports of groups of patients suffering from disseminated sclerosis being treated with steroids. In many of these studies there were no control patients and the results reported were equivocal. In $1961 \mathrm{H}$. Miller, D. J. Newell, and A. Ridley ${ }^{1}$ studied three comparable groups of patients over an eighteen-month period; 29 were given dummy tablets, 24 had nine soluble-aspirin tablets daily, and 26 had prednisolone $15 \mathrm{mg}$. daily, reduced after eight months to $10 \mathrm{mg}$. daily. Repeated examinations were made during the period of study, the degree of disability being recorded by the Alexander rating. ${ }^{2}$ The authors concluded that there was no statistical difference in the three groups between the numbers of acute exacerbations, nor between the numbers of new sympțoms and 